\title{
Reflexões sobre a inclusão escolar de uma criança com diag- nóstico de autismo na educação infantil
}

\begin{abstract}
Laura Kemp de Mattos*
Adriano Henrique Nuernberg**

\section{Resumo}

Esse trabalho visa relatar uma experiência de intervenção psicoeducacional no contexto escolar junto a uma turma de educação infantil. O foco principal foi auxiliar na promoção do desenvolvimento e da interação social de um educando com Transtorno Invasivo do Desenvolvimento (TID). O autismo leva a um funcionamento diferenciado do sujeito no tocante à reciprocidade social e comunicação, portanto, para que o educando possa participar das interações sociais foram necessárias mediações específicas articuladas com as características singulares da criança, valorizando a inter-regulação da participação do sujeito nas trocas sociais. Os resultados foram bastante expressivos, evidenciando a importância da mediação pedagógica no desenvolvimento psicossocial. De modo geral, foram observadas melhorias significativas na qualidade de interação e comunicação do educando em questão, bem como foram verificadas melhorias na capacidade da turma em acolher diferenças e da professora em flexibilizar suas práticas educacionais à luz de perspectivas inclusivas.
\end{abstract}

Palavras-chave: inclusão escolar; autismo; deficiência.

\section{Reflections about educational inclusion of a child with a diagnostic of autism in nursery schooling}

\begin{abstract}
This paper aims at relating a psychoeducational intervention experience of an educational context with a nursery school group. The principal focus was to help in the development promotion and social interaction of a student with Pervasive Developmental Disorder (PDD). Autism leads to differentiated behavior of the individual with regard to social and communication reciprocity and therefore specific mediations articulated with the singular characteristics of the child were necessary for the student to be able to participate in social interactions valorizing the inter-regulation of the individual's participation in social communication. The results were very meaningful and showed the importance of pedagogical mediation in psychosocial development. Significant improvement was observed in general in the interaction and communication quality of the student in question and furthermore improvements were noted in the capacity of the group in accepting the differences and of the teacher in terms of flexibility as to educational practices in light of the inclusion perspectives.
\end{abstract}

Keywords: educational inclusion; autism; disorder.

\footnotetext{
* Mestranda em Psicologia da Universidade Federal de Santa Catarina (UFSC), Florianópolis, Santa Catarina, Brasil.

** Professor Doutor do Departamento de Psicologia da Universidade Federal de Santa Catarina (UFSC), Florianópolis, Santa Catarina, Brasil.
} 


\section{Introdução}

O processo de inclusão escolar em contextos de educação infantil é ainda pouco investigado pela psicologia. Os estudos relacionados à temática geralmente se localizam na área do ensino (CONDE; CRUZ; OLIVEIRA, 2006; TETZCHNER et al., 2005). A psicologia, contudo, pode contribuir para esse debate de diferentes formas, incluindo a reflexão sobre o papel dos processos de inclusão escolar no desenvolvimento infantil.

Nesse âmbito, cumpre destacar que a inclusão de estudantes com deficiências no ensino regular promove um ambiente rico pela diversidade social e facilitador do desenvolvimento de todas as crianças. Nas relações concretas no contexto escolar, valores como respeito e cooperação podem ser experienciados pelas crianças quando a inclusão se efetiva. Ambientes bem planejados, que procuram se adequar às necessidades de todos os educandos compreendem a escola como meio sociocultural fundamental à constituição dos sujeitos. Se a interação social entre as crianças é indispensável para promover o desenvolvimento, cabe à escola viabilizar as possibilidades de experiências socializadoras, permitindo às crianças desenvolverem processos psicológicos superiores.

Por outro lado, a inclusão nos contextos educacionais requer uma intervenção psicopedagógica que enfatize a mediação semiótica na relação com o educando com deficiência (VYGOTSKI, 1997), de modo que ele possa se apropriar do universo cultural, por meio dos processos de significação ali entabulados (NUERNBERG, 2008). Nesse sentido, é possível discutir que o direito ao acesso ao conhecimento é também o direito de desenvolver-se de forma integral e apropriar-se das condições que favorecem a participação social de forma ativa, desde a educação infantil.

Para que a sociedade possa se adequar a todas as pessoas, independente de suas idiossincrasias, o trabalho interdisciplinar é indispensável. Portanto, uma possibilidade de parceria com a psicologia está justamente no diálogo entre a educação e a compreensão do desenvolvimento do psiquismo, possibilitando espaços reflexivos e viabilizando o entrelaçamento entre as áreas, contribuindo para propostas educacionais. Assim, o objetivo do trabalho aqui discutido foi contribuir para o processo de inclusão escolar, colaborando para o desenvolvimento e para a interação social de um educando com autismo, ${ }^{1}$ do sexo masculino, com 4 anos de idade e com severas dificuldades de comunicação.

\section{Psicologia histórico-cultural e intervenção educacional junto à crianças com autismo}

À luz da psicologia histórico-cultural, a constituição dos sujeitos tem sua gênese nas trocas sociais em contextos socioculturais. Esse modelo teóri$\mathrm{co}$, fundamento do presente estudo, tem sido bastante difundido e explorado pela produção científica brasileira (GÓES, 1991; 1997; PINO, 2000; ZANELLA, 
2003; 2004; CARNEIRO, 2006; ORRÚ, 2008; NUERNBERG, 2008). Nesse âmbito, compreende-se que as relações sociais possibilitam significações que são apropriadas pelos sujeitos, promovendo o desenvolvimento de formas de controle e organização dos processos psicológicos. Assim, a criança transcende o contexto imediato e pode agir sobre o meio social e físico com base em ferramentas simbólicas.

Nesse ínterim, a escola de educação infantil é mais um espaço de interação social que, portanto, constitui-se num meio sociocultural fundamental à constituição dos sujeitos. A inclusão de educandos com deficiências nesses espaços relaciona-se à criação de um ambiente pautado pela valorização da diversidade, procurando se adequar às necessidades de todos os estudantes. Assim, diante de educandos com deficiências devemos Ihes possibilitar processos de mediação ainda mais qualificados em relação aos signos mediadores, aos estímulos e aos desafios, os quais permitem o desenvolvimento dos processos psicológicos superiores (CARNEIRO, 2006).

A exclusão deste grupo social - as pessoas com deficiência - tem início desde a infância. Ainda hoje muitas crianças não frequentam escolas regulares e muitas daquelas que estão matriculadas enfrentam diversas barreiras $^{2}$ diárias. A intervenção da psicologia no cotidiano escolar, portanto, visa a superação dessas barreiras, principalmente as atitudinais, as quais se expressam por meio de preconceitos, estigmas e mitos que atuam sobre as pessoas com deficiência, marcando suas trocas sociais negativamente (AMARAL, 1998).

As primeiras descrições dos Transtornos do Espectro do Autismo (TEA) foram feitas por Leo Kanner (1943) e Hans Asperger (1944). Kanner constatou uma falta de habilidade dessas crianças para estabelecer relações interpessoais e dificuldades com a fala. Cumpre enfatizar que Kanner descreveu algumas características das crianças com autismo como: não haverem alterações físicas significativas, interesse por fotografias, insistência obsessiva em manter a rotina e rituais estereotipados. Asperger acrescentou mais algumas características, como por exemplo, a incapacidade em olhar para o outro nas trocas sociais (BOSA, 2002).

Contudo, a partir da década de 70 começam a serem realizados estudos mais sistemáticos sobre o autismo. A psiquiatra inglesa Lorna Wing propôs a noção de "espectro autista" para designar déficits qualitativos na denominada tríade de deficiências em todos os indivíduos, qual sejam, comunicação verbal e não-verbal, interação social e imaginação (BOSA, 2002; SACKS, 1995).

O Transtorno Autista é um dos Transtornos Invasivos do Desenvolvimento - TID de acordo com o DSM-IV-TR (AMERICAN PSYCHIATRIC ASSOCIATION, 2002). No entanto, o autismo é uma síndrome descrita há mais de seis décadas que ainda hoje não foi completamente compreendida. Diversas teorias visam explicar as possíveis causas e os sintomas decorrentes do autismo, 
sendo que atualmente as definições tendem a conceituá-lo como uma síndrome comportamental, de etiologias múltiplas (BOSA; CALLIAS, 2000).

Há ainda os estudos de Rivière (1995) a respeito das rupturas que crianças com autismo possuem no desenvolvimento da intersubjetividade secundária. Ao apresentarem dificuldades nos processos da intersubjetividade primária, ${ }^{3}$ observados pela ausência de reciprocidade social no momento do sorriso social quando bebês, bem como ausência de antecipação da conduta e pela menor frequência de respostas positivas à voz e ao contato tátil dos pais. Com isso, as crianças acabam também enfrentando dificuldades no desenvolvimento da intersubjetividade secundária, da função simbólica propriamente dita.

A partir do final da década de 90 uma possível conexão entre os recém descobertos neurônios-espelho e o autismo passou a ser verificada. Esses neurônios foram encontrados em muitas áreas cerebrais associadas ao movimento, percepção, empatia, compreensão das intenções dos outros e linguagem. Uma das regiões mais ricas em neurônios-espelho é justamente a área de Broca, responsável pelo processamento comunicacional. As pessoas com autismo, em geral, têm a atividade dos neurônios-espelho deficiente em todas as áreas, desde as mais básicas relacionadas a reconhecer a ação dos outros, até as mais complexas como reconhecer emoções, desenvolver linguagem e habilidades sociais (DOBBS, 2006; RAMACHANDRAN; OBERMAN, 2006).

Nesse sentido, cabe destacar também outras contribuições das teorias neuropsicológicas e de processamento da informação. No que tange ao processamento das informações sensoriais, à luz dessas teorias a tendência das crianças com autismo é por armazenar a informação visual, desenvolvendo um código visual, em detrimento dos códigos verbais e/ou auditivos. Outro aspecto enfatizado diz respeito à coerência central. Também é significativa a tendência dessas crianças por prestarem atenção aos detalhes, apresentando dificuldades em estabelecer as relações entre o todo e as partes (BOSA; CALLIAS, 2000).

A organização cerebral é muito complexa, diferentes partes do cérebro participam na realização de uma determinada atividade. Muitos dos sintomas do autismo podem ser explicados por um comprometimento no lobo cerebral frontal, mais especificamente na área pré-frontal (PARENTE, 2002). Essa área é a responsável pela função executiva, ou seja, pela capacidade de planejamento a partir de informações - sensoriais, atencionais e mnemônicas - recebidas pelas regiões posteriores do córtex, do sistema límbico ou do cerebelo.

Cumpre destacar a possível relação entre um déficit na função executiva e sintomas como as estereotipias e rotinas, pois a função executiva está relacionada à atenção compartilhada, "definida como a habilidade envolvendo a alternância do olhar e outros sinais comunicativos entre o parceiro e o objeto/ evento, que é o foco de atenção da criança" (BOSA, 2001, p. 04). A atenção compartilhada é uma importante habilidade para viabilizar o desenvolvimento da 
linguagem e da comunicação social. Os movimentos repetitivos surgem como uma alternativa à dificuldade dessa atenção e consequente comprometimento da função executiva.

No que tange à intervenção psicoeducacional com crianças com TID, ao longo da história ela foi muito desenvolvida pela abordagem comportamental da psicologia. O objeto de estudo dessa abordagem é o comportamento observável, determinado pela sua relação com o meio, na forma de estímulos antecedentes e consequentes, os quais fortalecem ou enfraquecem a frequência de emissão do comportamento. Entretanto, essa abordagem nem sempre considera a estrutura apropriada para estudar os diálogos, as negociações de sentido, o desenvolvimento da competência comunicativa e a interação social (TETZCHNER et al., 2005; ORRÚ, 2008).

Como dito anteriormente, a perspectiva histórico-cultural da constituição dos sujeitos demonstra que a gênese do psiquismo reside na interação sociocultural. Inicialmente as relações entre as pessoas possibilitam significações que viabilizam o desenvolvimento dos processos psicológicos superiores, sendo os sujeitos participantes do processo de criação de seu contexto social e a linguagem mediadora de suas relações (ORRÚ, 2008). Nesse sentido, as limitações orgânicas listadas podem ser compensadas por processos de natureza social, mediadas simbolicamente (NUERNBERG, 2008).

A linguagem é um sistema de sinais culturalmente estabelecidos e compartilhados, possibilitando a transmissão de conhecimentos e é decisiva na formação dos processos psicológicos. A teoria histórico-cultural de Vygotski ${ }^{4}$ aponta para a mediação semiótica como constitutiva do sujeito (ORRÚ, 2008). Deste modo, o sentido de uma palavra é um fenômeno de pensamento na medida em que ganha corpo por meio da fala e só é um fenômeno da fala na medida em que é ligada ao pensamento. "É um fenômeno do pensamento discursivo ou da palavra consciente, é a unidade da palavra e do pensamento" (VIGOTSKI, 2001, p. 398).

O desenvolvimento da linguagem, portanto, se dá como resultado das interações sociais. O que leva algumas crianças a precisarem de formas de comunicação alternativa é a ausência da fala, utilizando esses mecanismos como um "sistema de apoio para aquisição de linguagem" (TETZCHNER et al., 2005, p. 158). Nesse ínterim, as práticas inclusivas podem promover o desenvolvimento de linguagens alternativas em crianças com características diversas, sugerindo várias maneiras em que os pares possam interagir.

Cumpre enfatizar que na perspectiva da abordagem histórico-cultural o educando é sujeito ativo de seu processo de formação e desenvolvimento (GÓES, 1997). Portanto, o foco principal dessa intervenção é a apropriação da linguagem pelo educando, a partir do contexto sociocultural no qual está inserido, possibilitando ampliar sua autonomia e independência. 


\section{Descrição e análise da experiência}

A intervenção psicológica nesse contexto de educação infantil pretendeu auxiliar na superação das barreiras vivenciadas pelo educando com autismo e sua turma, principalmente com relação às barreiras atitudinais e às dificuldades comunicacionais. Promover diferentes meios de interação e de comunicação foi fundamental para a maior participação dele nas atividades. Nesse sentido, a diferença é uma condição humana e é imprescindível que a escola a contemple, ampliando possibilidades de ação para inserir plenamente as crianças nas relações sociais.

Este trabalho resultou de uma experiência de estágio curricular obrigatório em psicologia escolar, requisito para a formação em Psicologia, com duração de um ano, realizado junto a uma turma de educação infantil, auxiliando o trabalho da professora numa relação de parceria para promover a inclusão escolar. Inicialmente, para o planejamento e realização do estágio obrigatório, foram realizadas entrevistas com a professora e com os pais para identificar as situações vivenciadas em casa e na escola que caracterizam as barreiras comunicacionais encontradas na interação com o educando. As entrevistas foram gravadas, após autorização mediante termo de consentimento, transcritas e analisadas. Os dados foram obtidos a partir do entrelaçamento das diferentes informações, organizadas e classificadas em categorias de análise, decorrentes do diálogo estabelecido entre as entrevistas e, portanto, constituídas posteriormente para análise de conteúdo, conforme Franco (1994).

Nas entrevistas iniciais foi possível observar alguns aspectos da interação do educando na escola e em casa. Na entrevista com os pais, o pai ressaltou ser muito positivo esse projeto, porque lhe daria uma "ideia de como proceder em casa", pois "ficava limitado àqueles jogos de encaixe e quebracabeça". Nesses jogos a mãe disse perceber que ele ficava entediado e fazia por obrigação. Para ela "fica difícil atraí-lo. Nisso eu me senti carente de informações de como proceder" (Entrevista com os pais, 2008). Enfatizou-se a importância de brincarem junto com ele em casa. Nesse sentido, adaptar brinquedos aos interesses da criança pode estimular e facilitar esse processo.

No que tange especificamente à comunicação no contexto escolar, a professora disse durante a entrevista que ele não fala quase nada. "Teve um momento que ele resmungava quando queria alguma coisa. Ou falava "Dá, dá, dá...". Ou puxava a gente, mas não é como com as outras crianças quando querem alguma coisa. Às vezes ele aponta, mas só quando quer muito alguma coisa" (Entrevista com a Professora, 2008).

A estratégia de intervenção principal foi a inter-regulação da participação do sujeito nas trocas sociais. Essa inter-regulação foi bastante diretiva, não como recurso autoritário de disciplinamento, mas sim como parte de uma postura de co-ação, o que, num primeiro momento, a criança não é capaz de fazer isoladamente. Buscou-se a aplicação do princípio da dupla formação: primeiro 
fazer entre pessoas (intersubjetividades) para que o sujeito se aproprie dessa possibilidade de regulação, desenvolvendo uma possibilidade de autorregulação (intrassubjetividades).

Essa experiência propôs também a criação de modos diferenciados de comunicação como mecanismo auxiliar para a apropriação da linguagem pelo educando. O uso da comunicação alternativa visou promover o desenvolvimento da linguagem, com objetivo de facilitar sua inclusão escolar. O educando tinha sua comunicação restrita ao uso de gestos, como o gesto indicativo e apontando o que desejava. Ele emitia muitos sons, restritos a sílabas ou vogais isoladas que não formavam palavras. Foram poucas as palavras monossilábicas que ele pronunciou durante o período de intervenção como "não, dá e põe". Para Scheuer (2002, p. 55), as crianças com TID apresentam dificuldades "para fazer de sua comunicação um instrumento eficiente para dizer sobre suas necessidades, desejos, vontades". A autora observa ainda que a maioria destas crianças começa a falar tarde e o desenvolvimento da linguagem é bastante lento.

Perante a algumas situações, quando não compreendeu o que deveria fazer ou quando não conseguiu se expressar, o educando teve explosões emocionais e comportamentos autoagressivos. Diante dessas dificuldades comunicativas a sua reação emocional foi geralmente chorar, gritar, jogar-se no chão etc. Contudo, mesmo com tais dificuldades ele passou a compreender o significado de várias palavras, como quando perguntamos se podemos the dar um beijo, por exemplo, e ele vira o rosto, permitindo e demonstrando compreender algumas intenções dos outros.

Nesse sentido, foi indispensável desenvolver modos alternativos de comunicação para facilitar sua interação com as demais crianças e com os adultos envolvidos, além de auxiliar no desenvolvimento da linguagem e da autorregulação. Para Bosa (2002), o isolamento das crianças com autismo pode ser decorrente apenas de uma incompreensão do que está sendo solicitado. Em muitos momentos, isolar-se foi um recurso para não interagir, desencadeando rupturas em suas possibilidades de interação social. Essa barreira comunicacional prejudica as interações sociais, as práticas pedagógicas e as relações familiares, e estão presentes em todos os contextos nos quais a criança está inserida.

A partir do interesse do educando por imagens, imprimimos algumas fotografias da turma, nos diversos espaços da instituição e realizando atividades como desenhar, sentar em roda, lanchar, ir ao banheiro etc., com as palavras escritas abaixo indicativas das respectivas atividades. Em vários momentos foi perceptível que o recurso visual o auxiliou a compreender as atividades que deveriam ser realizadas, como nos registros a seguir:

As crianças deveriam lavar as mãos para lanchar. Ele não estava compreendendo, não queria ir. Chamei bem claramente, apontei o banheiro, mas ele fez cara de choro e ficou irritado. Então, o chamei e mostrei a foto 


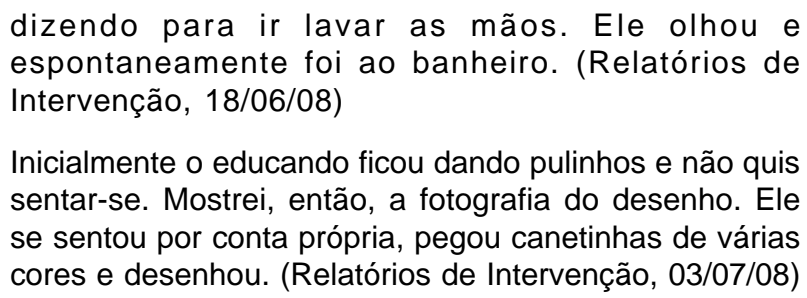
sentar-se. Mostrei, então, a fotografia do desenho. Ele se sentou por conta própria, pegou canetinhas de várias cores e desenhou. (Relatórios de Intervenção, 03/07/08)

A comunicação alternativa serve como "apoio na construção do signo, desde que mediada pelo professor [...] possibilita-se a essas crianças a construção de significados dentro de seus contextos e necessidades específicas, gerando a compreensão recíproca" (ORRÚ, 2007, p. 106). Ainda para a autora, "o que um aluno pode realizar em um momento com o auxilio de outra pessoa [...] poderá realizar futuramente sem tal auxílio" (p.161). Portanto, o objetivo foi, por meio da Zona de Desenvolvimento Proximal ${ }^{5}$ - ZDP, auxiliar no processo de aquisição da linguagem, utilizando a comunicação alternativa como instrumento, até que o educando adquira a linguagem verbal e não mais precise dela.

A partir da análise das entrevistas e registros cursivos do primeiro semestre de intervenção, foram planejadas e organizadas atividades semanais, com a duração média de 4 horas. Nesses encontros foram realizadas atividades coletivas, proporcionando momentos de interação social. Essas atividades foram videogravadas, após autorização dos pais, mediante termo de consentimento. Utiliza-se nesse estudo para registro dos dados o procedimento de videografia. Em seguida, foram realizadas análises microgenéticas do conteúdo das imagens, como tem sido frequente nos estudos em psicologia históricocultural (SMOLKA; GÓES, 1996; GÓES, 2000).

A partir das relações entre o objeto real, imagem fotográfica, ilustração, palavra verbal e escrita elaboraram-se atividades e brincadeiras para que 0 educando se apropriasse dessas relações culturalmente estabelecidas. Gradualmente fomos inserindo relações das mais simples até as mais complexas, mais distantes do objeto real, de modo a ampliar seu universo simbólico.

Os objetos, signos, símbolos e significados correspondentes que fazem parte do dia a dia das crianças foram organizados em cartões e compartiIhados entre elas. Esses cartões ficaram disponíveis para as crianças brincarem. Também foram adaptados jogos de quebra-cabeça, memória, histórias com desenhos etc. utilizando fotografias das crianças da turma, como modo de despertar o interesse do educando com autismo para a realização dessas atividades.

Além disso, foram construídos bonecos de jornal por cada criança, com fotos de seus rostos e foram produzidas miniaturas dos brinquedos do parque, como escorregador, balanço e gangorra para que pudessem brincar com os bonecos. Esses bonecos e brinquedos foram disponibilizados às crianças para que elas criassem no contexto da brincadeira situações de interação, as 
quais pudessem gradativamente expressar suas necessidades, desejos, de modo que o educando com autismo pudesse compreender e também se expressar, constituindo outro canal comunicativo.

Para cada material produzido, uma atividade foi planejada para inserilo no cotidiano escolar. Na atividade realizada com o objetivo de inserir os cartões ilustrativos dos objetos, brinquedos e alimentos para a comunicação alternativa, foram distribuídas palavras escritas para cada criança e no centro da roda os cartões foram dispostos, para que uma por uma elas procurassem as imagens correspondentes. Um dos colegas pegou a palavra "bolo" e encontrou o cartão equivalente. Quando o cartão foi mostrado para o educando com autismo, evidenciou-se o processo de desenvolvimento de sua linguagem, como pode ser observado no trecho a seguir, transcrito a partir do registro audiovisual da atividade:

\author{
Estagiária: Olha o bolo (Mostrando para ele o cartão e a \\ palavra escrita). Fala, bolo. \\ Educando: (Pegou o cartão, olhou atentamente) Pa, pa, \\ pa, pa, pa, pi (Batendo palmas). \\ Professora: O parabéns, vamos cantar. (Batendo palmas \\ e cantando). \\ Todos: Parabéns pra você, nessa data querida, muitas \\ felicidades, muitos anos de vida (Batendo palmas). \\ Professora: Muito bem, legal! \\ Educando: (Continuou com o cartão nas mãos).
}

Nas semanas seguintes histórias foram criadas e contadas pela professora, utilizando todo o material produzido. A história foi contada por meio dos cartões que eram mostrados para as crianças, passados de mão em mão e em seguida eram fixados num quadro branco. Para tanto, foi colocado velcro tanto nos cartões quanto no quadro. O educando com autismo ficou muito atento às histórias, olhou os cartões e até ajudou a fixar um deles. O seu interesse por imagens ficou ainda mais evidente, ele de fato estava incluído na atividade, participando atentamente.

Para a realização desse estágio, foram utilizados materiais, brinquedos e equipamentos disponíveis na escola de educação infantil como: jogos, músicas, histórias, papel, canetas, lápis, tintas, pincéis, tesoura, fita adesiva, papel cartão, cola branca, cola quente, papel contact, folhas de EVA, embalagens vazias, fotografias, computador, impressora etc. Desse modo, as barreiras comunicacionais e atitudinais presentes no contexto escolar foram redimensionadas, de modo a promover um ambiente inclusivo para todas as crianças.

Outros recursos, muito frequentemente utilizados pelo educando como forma de diminuir a ansiedade diante de situações sociais, foram os movimentos repetitivos e estereotipados, como observar o movimento de pequenos ga- 
Ihos ou olhar para o ventilador, por exemplo. As outras crianças ficavam curiosas com esses movimentos e por vezes o imitaram na tentativa de compreender a motivação que o levava a observá-los. Passaram a ajudá-lo a encontrar os gaIhos ideais, mesmo que não "gostassem" de brincar como ele.

As estereotipias podem assumir diferentes funções, dependendo da situação. Para Bosa (2002, p. 36), "um mesmo comportamento pode servir a diferentes funções: extravasamento de tensão, comunicação de desejos e necessidades, formas de protesto ou mesmo de resposta a demandas sociais". Pode-se inferir que tais recursos foram utilizados diariamente pelo educando, contudo, suas reações emocionais quando solicitado que parasse, para inserilo nas atividades, foram tornando-se mais amenas até que não mais existissem.

Os resultados foram avaliados a partir de indicadores pautados por duas categorias principais: a qualidade das interações sociais e a qualidade dos processos de comunicação, os quais foram identificados por meio das iniciativas de reciprocidade social e pelos episódios de verbalização protagonizados pela criança. Para tanto, foram utilizados registros cursivos em situações de observação sistematizada e registros audiovisuais para colher as informações.

Cumpre destacar a excelente postura profissional da professora disposta a incluí-lo nas atividades desde o início do trabalho. Foram verificadas melhorias significativas na sua capacidade de acolher as diferenças, bem como flexibilizar suas práticas educacionais à luz de perspectivas inclusivas. Outros sujeitos fundamentais nesse processo foram as demais crianças da turma. As trocas sociais e comunicativas entre elas foram essenciais para a efetiva inclusão escolar, demonstrando serem muito profícuas as interações entre os pares no contexto escolar para o desenvolvimento do educando com autismo. Também para elas foi importante a vivência da valorização da diversidade, de modo a superarem as barreias comunicacionais e atitudinais.

\section{Considerações finais}

Uma das contribuições dessa experiência foi a evidência da importância da mediação pedagógica nas trocas sociais, de modo a garantir que as barreiras existentes não impeçam a plena participação do educando com TID. O autismo leva a um funcionamento diferenciado do sujeito no tocante às competências e habilidades sociais (WATT, 2008), portanto, para que o educando pudesse participar das interações sociais foram necessárias mediações específicas, articuladas com as características singulares da criança.

Os resultados foram bastante expressivos das possibilidades de efetivação de trocas sociais no contexto escolar. No início desse trabalho, a interação social, que era praticamente inexistente, foi se tornando possível a partir do brincar e do auxílio proporcionado à comunicação. A brincadeira se configurou como um canal comunicativo em que trocas sociais passaram a ser realizadas no contexto escolar. 
No que tange aos modos diferenciados de comunicação, buscou-se possibilitar o desenvolvimento da linguagem, com objetivo de facilitar sua inclusão escolar. Os adultos envolvidos e, posteriormente, as crianças da turma auxiliaram ativamente nos processos de comunicação, colaborando para o desenvolvimento das relações sociais e dos processos psicológicos superiores do educando com deficiência.

A diferença é inerente à condição humana e sua valorização é fundamental para a educação, com vistas a inserir todas as crianças nas relações sociais. A inclusão visa à modificação dos contextos sociais como pré-requisito para possibilitar o desenvolvimento pessoal e social das crianças com deficiências, garantindo possibilidades de exercício da cidadania. Com o investimento em processos inclusivos, pretende-se uma ampliação nas possibilidades de participação das pessoas com deficiência ao convívio social, sem segregá-las em instituições especiais, mas contribuindo para legitimá-las como cidadãos. Para tanto, o trabalho interdisciplinar é indispensável e a parceria da educação com a psicologia demonstrou como essa experiência ser muito profícua.

\section{Referências}

AMARAL, L. Sobre crocodilos e avestruzes: falando de diferenças físicas, preconceitos e sua superação. In: AQUINO, J. Diferenças e preconceitos na sala de aula. São Paulo: Ed. Summus, 1998. p. 11-29.

AMERICAN PSYCHIATRIC ASSOCIATION. Manual diagnóstico e estatístico dos transtornos mentais - DSM-IV-TR. Porto Alegre: Artmed, 2002.

BOSA, C. As Relações entre Autismo, Comportamento Social e Função Executiva. Psicologia: reflexão e crítica. Porto Alegre, v. 14, n. 2, 2001.

. Autismo: Atuais interpretações para antigas observações. In: BAPTISTA, C. R.; BOSA, C. Autismo e Educação: reflexão e propostas de intervenção. Porto Alegre: Artmed, 2002.

BOSA, C.; CALLIAS, M. Autismo: breve revisão de diferentes abordagens. Psicologia: reflexão e crítica. Porto Alegre, v.13, n.1, 2000.

CARNEIRO, M. S. C. A deficiência mental como produção social: de Itard à abordagem histórico-cultural. In: BAPTISTA, C. R. Inclusão e escolarização. Porto Alegre: Mediação, 2006, p. 137-152.

CONDE, P. S.; CRUZ, C.; OLIVEIRA, R. I. Inclusão na educação infantil: Tessituras de concepções e fazeres pedagógicos. Seminário Capixaba de Educação Inclusiva: 10 anos de educação inclusiva no Espírito Santo. Anais, Vitória: UFES, 2006, p. 306.

DOBBS, D. Reflexo Revelador. Mente \& Cérebro. Scientific American Brasil. ano XIV, n. 161, p. 46-51, Junho de 2006. 
FRANCO, M. L. P. B. O que é análise de conteúdo In: FRANCO, M. L. P. Ensino médio: desafios e reflexões. 1. ed. Campinas: Papirus, 1994, p. 155-180.

GÓES, M. C. A natureza social do desenvolvimento psicológico. Cadernos CEDES, Campinas, n. 24, p. 17-24, 1991.

. As relações intersubjetivas na construção de conhecimentos. In: GÓES, M. C. R. et al. A significação nos espaços educacionais. Campinas: Papirus, 1997, p. 11-28.

. A abordagem microgenética na matriz histórico-cultural: uma perspectiva para o estudo da constituição da subjetividade. CENTRO DE ESTUDOS EDUCAÇÃO E SOCIEDADE. Relações de ensino: Análises na perspectiva histórico-cultural. Campinas: CEDES Unicamp, 2000.

NUERNBERG, A. H. Contribuições de Vigotski para a educação de pessoas com deficiência visual. Psicologia em estudo, Maringá, v. 13, n. 2, p. 307-316, abr./jun. 2008.

ORRÚ, S. E. Autismo, linguagem e educação: Interação Social no Cotidiano Escolar. Rio de Janeiro: Wak Ed., 2007.

. Os estudos da análise do comportamento e a abordagem histórico$\overline{c u l t u r a l}$ no trabalho educacional com autistas. Revista Iberoamericana de Educación. n. 45/3, 25 de fevereiro de 2008.

PARENTE, M. A. M. P. Organização cerebral das funções cognitivas envolvidas na sociabilização. In: BAPTISTA, C. R.; BOSA, C. A. Autismo e educação: reflexão e propostas de intervenção. Porto Alegre: Artmed, 2002.

PINO, A. O social e o cultural na obra de Vigotski. Educação e Sociedade, n. 71 , p. $45-78,2000$.

RAMACHANDRAN, V. S.; OBERMAN, L. M. Espelhos quebrados: uma teoria sobre o autismo. Scientific American Brasil. Ano 5, n. 55, dezembro de 2006.

RIVIÈRE, A. O desenvolvimento e a educação da criança autista In: COLL, Palacios, Jesús; MARCHESI, A., Desenvolvimento psicológico e educação: necessidades educativas especiais e aprendizagem escolar. Porto Alegre: Artes Médicas, 1995, p. 272-291.

SACKS, O. Um antropólogo em Marte. São Paulo: Schwarcz, 1995.

SASSAKI, R. K. Como chamar as pessoas que têm deficiência? In: SASSAKI, R. K. Vida independente: história, movimento, liderança, conceito, filosofia e fundamentos. São Paulo: RNR, 2003, p. 12-16.

SCHEUER, C. Distúrbios da Linguagem nos Transtornos Invasivos do Desenvolvimento. In: BAPTISTA, C. R.; BOSA, C. A. Autismo e educação: reflexão e propostas de intervenção. Porto Alegre: Artmed, 2002. 
SMOLKA, A. L.; GÓES, M. C. R. A linguagem e o outro no espaço escolar: Vygotsky e a construção do conhecimento. Campinas: Papirus, 1996.

TETZCHNER, S. V. et al. Inclusão de crianças em educação pré-escolar regular utilizando Comunicação suplementar e alternativa. Revista Brasileira de Educação Especial, Marília, v. 11, n. 2, p.151-184, mai./ago. 2005.

VIGOTSKI, L. S. A construção do pensamento e linguagem. São Paulo: Martins Fontes, 2001.

VYGOTSKI, L. S. Obras Escogidas V: Fundamentos de defectología. Madrid: Visor, 1997.

. A formação social da Mente. São Paulo: Martins Fontes, 1991.

WATT, N. et al. Repetitive and stereotyped behaviors in children with autism spectrum disorders in the second year of life. Journal of Autism and Developmental Disorders, v. 38, n. 8, p. 1518-1533, 2008.

ZANELLA, A. V. Reflexões sobre a Atuação do(a) Psicólogo(a) em Contextos de Escolarização Formal. Psicologia: ciência e profissão, v. 23 (3), p. 68-75, 2003.

. Atividade, significação e constituição do sujeito: considerações à luz da psicologia histórico-cultural. Psicologia em estudo, n. 1, p. 127-135, 2004.

Notas

1 Neste trabalho optou-se por privilegiar o termo pessoa com deficiência, no caso específico educando ou criança com autismo, devido a seu uso corrente no contexto dos movimentos sociais (SASSAKI, 2003).

2 A metáfora de "barreira" tem sido usual no contexto da inclusão escolar como forma de identificar as limitações físicas, pedagógicas, comunicacionais e atitudinais presentes nos contextos educacionais.

${ }^{3}$ Conceito que diz respeito às características do desenvolvimento que evidenciam a propensão da criança normal em interagir socialmente.

${ }^{4}$ Utiliza-se essa grafia do nome do autor russo, como tem sido usual na literatura atual que faz referência a sua obra, respeitando a grafia original das obras consultadas.

5 "Zona de Desenvolvimento Proximal [...] é a distância entre o nível de desenvolvimento real, que se costuma determinar através da solução independente de problemas, e o nível de desenvolvimento potencial, determinado através da solução de problemas sob a orientação de um adulto ou em colaboração com companheiros mais capazes" (VYGOTSKY, 1991, p. 97).

Correspondência

Laura Kemp de Mattos - Rua Hercílio Pires, n. 91, Florianópolis, Santa Catarina, Brasil. CEP: 88066-295.

E-mail: kemp.laura@gmail.com

Recebido em 02 de setembro de 2010

Aprovado em 28 de março de 2011 